NASA/TM-2002-211090

Lead Removal From Synthetic Leachate Matrices by a Novel Ion-Exchange Material

Kenneth W. Street, Jr.

Glenn Research Center, Cleveland, Ohio

Edward S. Hovanitz

Engelhard Corporation, Elyria, Ohio

Sulan Chi

Eli Lilly \& Company, Clinton, Indiana

July 2002 
The NASA STI Program Office ... in Profile

Since its founding, NASA has been dedicated to the advancement of aeronautics and space science. The NASA Scientific and Technical Information (STI) Program Office plays a key part in helping NASA maintain this important role.

The NASA STI Program Office is operated by Langley Research Center, the Lead Center for NASA's scientific and technical information. The NASA STI Program Office provides access to the NASA STI Database, the largest collection of aeronautical and space science STI in the world. The Program Office is also NASA's institutional mechanism for disseminating the results of its research and development activities. These results are published by NASA in the NASA STI Report Series, which includes the following report types:

- TECHNICAL PUBLICATION. Reports of completed research or a major significant phase of research that present the results of NASA programs and include extensive data or theoretical analysis. Includes compilations of significant scientific and technical data and information deemed to be of continuing reference value. NASA's counterpart of peerreviewed formal professional papers but has less stringent limitations on manuscript length and extent of graphic presentations.

- TECHNICAL MEMORANDUM. Scientific and technical findings that are preliminary or of specialized interest, e.g., quick release reports, working papers, and bibliographies that contain minimal annotation. Does not contain extensive analysis.

- CONTRACTOR REPORT. Scientific and technical findings by NASA-sponsored contractors and grantees.
- CONFERENCE PUBLICATION. Collected papers from scientific and technical conferences, symposia, seminars, or other meetings sponsored or cosponsored by NASA.

- SPECIAL PUBLICATION. Scientific, technical, or historical information from NASA programs, projects, and missions, often concerned with subjects having substantial public interest.

- TECHNICAL TRANSLATION. Englishlanguage translations of foreign scientific and technical material pertinent to NASA's mission.

Specialized services that complement the STI Program Office's diverse offerings include creating custom thesauri, building customized data bases, organizing and publishing research results ... even providing videos.

For more information about the NASA STI Program Office, see the following:

- Access the NASA STI Program Home Page at http://www.sti.nasa.gov

- E-mail your question via the Internet to help@sti.nasa.gov

- Fax your question to the NASA Access Help Desk at 301-621-0134

- Telephone the NASA Access Help Desk at 301-621-0390

- Write to: NASA Access Help Desk NASA Center for AeroSpace Information 7121 Standard Drive Hanover, MD 21076 
NASA/TM-2002-211090

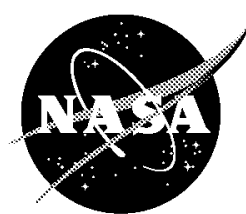

Lead Removal From Synthetic Leachate Matrices by a Novel Ion-Exchange Material

Kenneth W. Street, Jr.

Glenn Research Center, Cleveland, Ohio

Edward S. Hovanitz

Engelhard Corporation, Elyria, Ohio

Sulan Chi

Eli Lilly \& Company, Clinton, Indiana

National Aeronautics and

Space Administration

Glenn Research Center

July 2002 


\section{Acknowledgments}

This work was funded wholly by the United States Environmental Protection Agency under Contract Number DW80936188-01-0 to the National Aeronautics and Space Administration, Lewis Research Center.

Trade names or manufacturers' names are used in this report for identification only. This usage does not constitute an official endorsement, either expressed or implied, by the National Aeronautics and Space Administration.

Available from

NASA Center for Aerospace Information 7121 Standard Drive

Hanover, MD 21076
National Technical Information Service 5285 Port Royal Road Springfield, VA 22100

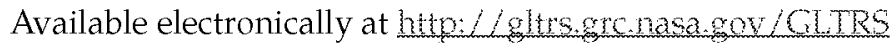




\title{
Lead Removal From Synthetic Leachate Matrices by a Novel Ion-Exchange Material
}

\author{
Kenneth W. Street, Jr. \\ National Aeronautics and Space Administration \\ Glenn Research Center \\ Cleveland, Ohio 44135 \\ Edward S. Hovanitz \\ Engelhard Corporation \\ Elyria, Ohio 44035 \\ Sulan Chi \\ Eli Lilly \& Company \\ Clinton, Indiana 47842
}

\begin{abstract}
Summary
This report discusses the application of a novel polyacrylate-based ion-exchange material (IEM) for the removal of lead $(\mathrm{Pb})$ ions from water. Preliminary testing includes the establishment of the operating $\mathrm{pH}$ range, capacity information, and the effect of calcium and anions in the matrix. Batch testing with powder indicates slightly different optimal operational conditions from those used for column testing. The ion exchanger is excellent for removing lead from aqueous solutions.
\end{abstract}

\section{Implications}

This work demonstrates the ability of a polyacrylate ion-exchange material to remove toxic metals from water. The material has significant affinity for lead in the presence of considerable amounts of competing or complexing ions, and it also works well in the presence of hard water to readily remove other toxic metals. An important property of this material is that it can be fabricated in many forms, such as coatings, films, and conventional beads.

\section{Introduction}

Lead $(\mathrm{Pb})$ in the water supply is an ever-increasing concern. Common sources include the corrosion of transport systems and material leached from the environment. The environmental sources are diverse, ranging from lead paint in the soil to spillage at battery cracking facilities. ${ }^{1,2}$ Because of the extreme toxicity of lead, acceptable concentration levels of lead in potable water must be maintained at low parts per billion. One of the most common techniques for lowering the concentration of metal ions to suitable levels in potable water is ion-exchange treatment.

In the environment, a proposed method of remediation technology is soil washing. This treatment appears to be extremely attractive because of the large quantities of contaminated soil that would otherwise have to be contained in a waste storage facility. ${ }^{2,3}$ In soil washing, the soil is pretreated to remove large lead sources (e.g., bullets). The corroded lead that has leached into the soil is stripped with a leachant. Because the lead encountered in different washing situations occurs in different forms, the wash solution must be tailored to the site. Typical wash solutions that have been employed range from a simple acidification medium, such as dilute nitric or fluosilicic acid, to strong complexing agents, such as ethylenediaminetetraacetic acid (EDTA). Although EDTA has been shown to solubilize lead fairly well, it creates other problems with the soil to be subsequently recovered. Weak chelators have been employed as well, including nitrilotriacetic acid and acetic acid. The acetic acid is attractive as it is inexpensive, has been demonstrated to be a moderately good leachant, and is readily biodegradable. The leachate is then stripped 
by ion-exchange technology and recycled. This last step in the loop is often problematical, since a good leachant is often hard to strip of the solubilized lead.

A novel polyacrylate based ion-exchange material (IEM) was developed at NASA after the serendipitous discovery that a marginal battery separator retained copper ions from distilled water. The source of the copper in the distilled water used to wash the separator was traced to a corroding line in the still. In earlier versions of the separator, polyacrylic acid was cross-linked with radiation to produce films. These materials had ion-exchange capacity but were readily fouled prior to reaching a useful loading capacity. ${ }^{4-7}$ In subsequent versions of the material, polyvinyl alcohol was incorporated in the film matrix, which solved the fouling problem. ${ }^{8,12}$ The new ion-exchange material is chemically cross-linked at the polyvinyl alcohol leaving the polyacrylic acid loosely trapped in the matrix. This configuration of the material provides additional flexibility for the polyacrylic acid sites to exchange ions.

We have characterized the new ion-exchange material for removal of lead in the presence of various anions that are commonly found in the environment. Chloride was also tested because it is ubiquitous and will be of interest in systems where noncomplexing leachants such as nitric acid are employed. Acetic acid was investigated as a weak complexing agent associated with proposed soil-washing scenarios. The study includes the effects of $\mathrm{pH}$ because it is important when using weak cation exchangers and the calcium ion, which often fouls ion exchangers. For comparison, limited data on copper and zinc are also presented.

\section{Materials and Methods}

The ion-exchange resin was obtained from Southwest Research Institute, San Antonio, Texas. The powder was manufactured by spray-drying a solution containing 8.4 percent solids (1:1 mixture of polyvinyl alcohol (PVA) and polyacrylic acid (PAA)) and 0.13 percent glutaraldehyde to cross-link the polyvinyl alcohol framework. ${ }^{8,12}$ The ion-exchange beads were manufactured by a novel patented process. ${ }^{13}$ The aqueous phase contained 14 percent solids (1:1 mixture of polyvinyl alcohol and polyacrylic acid) and 1.3 percent glutaraldehyde. This solution was mixed with mineral oil and fumed silica in a sufficient amount to cause droplets of resin to remain suspended after stirring stopped. The mixture was heated to 60 to $70^{\circ} \mathrm{C}$ overnight. The spheres were strained, washed with hexane, and air dried. All ion-exchange materials were received in the acid form. Prior to use in uptake experiments, they were converted to the calcium form. Powder was stirred with excess suspended calcium hydroxide, filtered and washed prior to use. Bead conversion is described below.

The capacity of the ion-exchange materials was determined by equilibrating the acid IEM with an excess of standard sodium hydroxide for at least $12 \mathrm{hr}$. The resin was filtered off and the excess hydroxide was determined by titration with standard hydrochloric acid. For batch tests, the ion-exchange material (typically $100 \mathrm{mg}$ ) was stirred with the test solution (typically $100 \mathrm{ml}$ ) and aliquots were taken at defined time intervals. An aliquot was taken prior to the introduction of the ion-exchange material to the test. The amount taken was such that all aliquots totaled less than 5 percent of the original volume. Metal ion concentrations were determined on all aliquots by flame or graphite furnace atomic absorption spectrophotometry (AAS) using the conditions described in SW- $846^{14}$ or as close as possible. The $\mathrm{pH}$ was determined at the start and end of each experiment. ${ }^{15}$

Column testing was performed in glass columns with sintered glass frits at either end. The columns were typically packed with $1 \mathrm{~g}$ of beads 80 percent converted to the calcium form. Challenge solutions containing various concentrations of lead and lead with excess anions at varying $\mathrm{pH}$ were pumped continuously through the column. The effluent was collected for AAS and $\mathrm{pH}$ analysis. The ion-exchange material was weighed in the acid form, converted to the correct extent with standard calcium hydroxide solution, and loaded into the column. The void volume of the column was monitored by the injection of a salt spike to generate a signal at a conductivity detector placed at the column effluent. Challenge solutions were prepared from the lead salts with the corresponding anion. To prevent hydrolysis and subsequent precipitation of the lead, the solutions were stabilized with a trace of hexamethylenetetramine (a weak complexing agent). The $\mathrm{pH}$ was then adjusted with nitric acid. For challenge solutions containing excess anion, the solution was prepared such that an excess of 0.1 -molar anion was generated from 0.09-molar sodium salt and 0.005-molar calcium salt. Various challenge solutions, column geometries, and flow conditions were tested as described in the subsequent sections and figures. 


\section{Results}

The powder form of the IEM, nominally in the 5- to $75-\mu \mathrm{m}$ range, was used as received. Titration of this material indicated a capacity of $4.81 \pm 0.11 \mathrm{meq} / \mathrm{g}$ IEM. Equilibration of the calcium form of the IEM with a large excess of copper ions in an acetate buffer at $\mathrm{pH} 5.0$ yielded a capacity of $4.8 \mathrm{meq} / \mathrm{g}$ IEM. Titration of two subsequent lots of powder yielded capacities of 5.29- and 5.36-meq/g IEM. By end point differences in the back titration of these materials, it is possible to determine the amount of polyacrylic acid released from the cross-linked polyvinyl alcohol during the reaction with the sodium hydroxide. The leakage numbers correspond to $1.72,0.86$, and $1.05 \mathrm{meq} / \mathrm{g}$, respectively, indicating that the latter lots of IEM were cross-linked more efficiently and therefore yielded the higher capacities with lower leakage.

Figure 1 demonstrates the $\mathrm{pH}$ working range for the powder form of the IEM using copper and lead as test ions. Figure 2 illustrates the rate at which the powder and film forms of the IEM take up lead ions in batch testing. For comparison, the sodium form of the Biorad cation-exchange resin ( $\mathrm{AG} 50 \mathrm{~W}-\mathrm{X} 2,38$ to $75 \mu \mathrm{m}$ ) for uptake of copper ions is also presented. Table 1 summarizes the results of 16 separate conditions tested and demonstrates the immunity of the IEM against some common anions for the uptake of lead ions when $100 \mathrm{mg}$ of IEM powder is challenged with $100 \mathrm{ml}$ of test solution under the conditions specified in the table.

The beads received from Southwest Research Institute were fractionated into two sizes (600 to $1400 \mu \mathrm{m}$ and $<600 \mu \mathrm{m}$ ). These were presumably manufactured as one lot having a similar composition. The $<600-\mu \mathrm{m}$ lot was further sized into two fractions, $<250 \mu \mathrm{m}$ and 250 to $600 \mu \mathrm{m}$. The limited quantity of the latter fraction was saved for testing in column experiments and was then recycled for capacity testing. The other two fractions were subjected to several batch experiments. Table 2 gives capacity and leakage values for the limited testing performed on these materials. It is apparent that the recycled beads give considerably lower leakage values and that the capacity is in line with that of the original material. Digestion of the beads resulted in a silica content of approximately 10 percent by weight from entrapped silica introduced during the manufacturing process.

For comparison, the beads packed into the columns were weighed and the column dimensions were recorded along with the experimentally measured void volumes. Typically, $1.00 \mathrm{~g}$ of the 80 -percent converted beads packed into a $10-\mathrm{mm}$-inside-diameter (id) column produced a bed $60 \mathrm{~mm}$ long $(4.7 \mathrm{ml})$ with a void volume of $2.5 \mathrm{ml}$. The bulk density of the beads was then calculated to be $0.2 \mathrm{~g} / \mathrm{cm}^{3}$ (dry) and the void volume to be 53 percent. In most cases, the length of the bed decreased by 2 to $3 \mathrm{~mm}$ by the end of the experiment.

Two different experiments compared beads that were converted to the 20 - and 80 -percent calcium forms. Figure 3 is a plot of the lead concentration of the exit $C_{e}$ divided by the initial challenge concentration $C_{i}$ versus the volume of lead solution run through the column. It is apparent that breakthrough occurs early with the 20 -percent converted beads. Even at a very low challenge concentration $(100 \mathrm{ppm})$, the 20 -percent converted beads are not as effective at removing lead as is the 80 -percent converted material. The behavior of the columns is understood by close examination of the associated $\mathrm{pH}$ profile of the effluent during a column experiment. In figure 4 , the effluent $\mathrm{pH}$ is plotted for the two 500-ppm Pb samples in figure 3. Figure 4 demonstrates the relationship between percent of bead conversion to the calcium form and ability to maintain $\mathrm{pH}$ as lead is removed from the influent solution.

A careful examination of the $\mathrm{pH}$ profiles for all column tests performed with the 80 -percent converted IEM and lead solutions containing chloride or nitrate is shown in figure 5. This figure is a plot of the pH of the first eluent collected $\mathrm{pH}_{\mathrm{e}}$ from the column versus the $\mathrm{pH}$ of the influent challenge solution $\mathrm{pH}_{\mathrm{i}}$. The figure reveals that the resin initially attempts to adjust the $\mathrm{pH}$ of the solution in the column to a value coincidentally close to the $\mathrm{pK}_{\mathrm{a}}$ of the IEM, approximately 5.5. A plot of $\left(\mathrm{pH}_{\mathrm{i}}-\mathrm{pH}_{\mathrm{e}}\right)$ versus the $\mathrm{pH}$ of the challenge solution $\mathrm{pH}_{\mathrm{i}}$ is presented in figure 6 . This plot demonstrates the amount of $\mathrm{pH}$ adjustment on the solution by the column.

Figure 7 shows typical breakthrough curves for columns of varying length and the effect of nitrate ions. Excess nitrate ions only influence this system by providing a high ionic strength. In subsequent experiments, the longer length columns were used because they provided more ideal curves. For comparison, the weights of resin used to vary the column length are included in the legend to the figure. It is also evident that the high ionic strength improves the performance of the IEM generally. In another experiment (not shown), the effect of ionic strength was a doubling of the apparent onset of column breakthrough for two flow rates. Figure 8 shows the effect of flow rate on column retention of lead. Figure 9 is a plot of the lead in the IEM at the end of the experiment normalized by the weight of IEM used in the experiment plotted against the final reading of $\mathrm{C}_{\mathrm{e}} / \mathrm{C}_{\mathrm{i}}$ for 30 column experiments. The large scatter in the data is attributable to varying conditions of flow rate, column length, $\mathrm{pH}$, anion associated with the $\mathrm{Pb}$ salt, and in some cases, 0.1-molar excess of the corresponding anion. Extrapolation of the data having 
$\mathrm{C}_{\mathrm{e}} / \mathrm{C}_{\mathrm{i}}>0.01$ (22 data points) to $\mathrm{C}_{\mathrm{e}} / \mathrm{C}_{\mathrm{i}}=0$ indicates that $\mathrm{Pb}$ loading of about 10 percent by weight (approx. 20 percent of the calculated equilibrium capacity) leads to breakthrough in unoptimized conditions. In the most extreme data, at $\mathrm{C}_{\mathrm{e}} / \mathrm{C}_{\mathrm{i}}>0.8$, the resin has, at best, taken up 28 percent of its weight as lead, which is only 60 percent of the calculated equilibrium capacity.

The effect of chloride was examined because it is ubiquitous, has complexing ability, and forms a sparingly soluble salt with lead. Acetate is of interest as acetic acid has been used in soil washing scenarios. Acetate has moderate complexing ability and acts as a solution buffering agent. Figure 10 presents additional data for column experiments involving chloride and acetate.

\section{Discussion}

Preliminary investigations with laboratory samples of the ion-exchange material indicated that it has the following properties: high capacity; mechanical durability; immunity to calcium; immunity to iron and several other nontoxic metal ions; high efficiency in the removal of lead, cadmium, and other toxic metal ions; easy recyclability or disposability; and easy formation into many shapes (e.g., beads, fibers, film, or coated magnetic beads). ${ }^{8-12}$ Because of these properties, we decided to have the material manufactured by a commercially scalable process for evaluation as a potentially useful product. Proposed uses include drinking water purification and application in environmental processes such as soil washing. To date, powder, beads, film (both porous fiberglass-reinforced and nonporous), and irregular granules have been produced at the pilot scale. These potential products indicate that the manufacturing process for this material is feasible.

\section{Powder Properties}

The capacity numbers are consistent with the theoretically calculated value of just under $7 \mathrm{meq} / \mathrm{g}$ for a material containing 50 percent PAA. From prior experimentation with bead, granular, powder, and film IEM, there are a number of reasons for the leakage. ${ }^{12}$ A small amount of initial leakage appears to be inherent in the structure of the material in that the PVA is cross-linked into a matrix that entangles the PAA, the only mechanism for retention of the PAA in the resin. Some small amount of additional PAA leaks during the first conversion to the salt form, the active form of the resin. The conversion process with calcium tends to shrink the resin, which causes the remaining PAA to be more strongly retained in the resin so that subsequent leakage is negligible. Consequently, the working version of the IEM uses the calcium salt, which is immune to leakage and deterioration of mechanical strength. Conversion with sodium hydroxide as in the titrations tends to expand the volume of the resin (prior unpublished studies indicate by as much as 40 percent), causing deterioration of the mechanical strength. Sodium conversion may also release more PAA than the working calcium form. Hence, the leakage numbers may be an overestimate and the actual capacities reported may be underestimates. In the formulation process, we have also observed that too little crosslinking and/or using a PAA with lower molecular weight facilitates leakage. This topic will be further addressed in the section Bead Properties.

The IEM is a weak acid cation-exchange resin estimated to have a $\mathrm{pK}_{\mathrm{a}}$ of approximately 5.5. The operational $\mathrm{pH}$ range for the IEM (fig. 1) is limited at lower $\mathrm{pH}$ values as acid competes heavily for the resin sites. The powder does not appear to suffer the same shortcoming described in our earlier work where many metal ions that exist as neutral precipitates or as anionic hydroxy species at the higher $\mathrm{pH}$ values (typically $\mathrm{pH}>7$ ) are not taken up by the film form of the IEM. In the present work, the powder IEM clearly removed copper effectively to a $\mathrm{pH}$ approaching 8. In our earlier work with films, ${ }^{9}$ the copper recovery had dropped from nearly 100 percent at pH 6.5 to 50 percent at a $\mathrm{pH}$ slightly greater than 7 . The extended operational $\mathrm{pH}$ range is probably due to the higher surface area of the powder, hence the better performance. The slowness in uptake for the film versus the powder (fig. 2) is attributed to mass transfer problems associated with the film's being a single entity in a large volume of solution. Nonetheless, it is as effective at removing ions provided that there is sufficient equilibration time. At the lower $\mathrm{pH}$ values, the anions evaluated in table 1 are less problematical than the $\mathrm{pH}$. At higher $\mathrm{pH}$ values, the acetate, which has a high formation constant with lead, ${ }^{16}$ lowers the effectiveness of the IEM as discussed in the section Column Performance. 


\section{Bead Properties}

Beads would be expected to have a 10-percent lower capacity than the powder due to the silica incorporated during manufacturing. The rest of the capacity reduction in the beads is attributable to a lack of bead porosity and the resulting mass diffusion problems. For the purpose of comparison later, the calculated uptake of lead based on a capacity of $4.3-\mathrm{meq} / \mathrm{g}$ IEM is 45 percent of the weight of the IEM. From prior comparative studies with the film and with irregular granular and powder forms of the IEM, the majority of the performance properties (e.g., $\mathrm{pK}_{\mathrm{a}}$ of the IEM, capacity, affinity for metal ions, and $\mathrm{pH}$ uptake profiles for various metals) are very similar. The two exceptions are the kinetic-related properties and the apparent extended operating $\mathrm{pH}$ range for the powder demonstrated in the single experiment reported herein (fig. 1).

\section{Column Performance}

Even though the columns prepared with 20 -percent converted beads do not work well at high-challenge concentrations, figure 3 demonstrates that a substantial amount of lead can be removed for low-challenge concentrations with a 20 -percent converted material. The key to the behavior of the columns is that the resin behaves as a $\mathrm{pH}$ buffer by altering the $\mathrm{pH}$ of the medium passing through the column, as seen in figure 4 . For water at a $\mathrm{pH}$ of 5 passing through an 80-percent converted column (approx. IEM pH of 6.6), the column would be expected to pick up hydrogen ions from the medium and release calcium from the resin. This behavior should result in a slight increase in the $\mathrm{pH}$ of the column effluent; however, this activity is not what was observed. For lead solutions passing through the column, the lead was exchanged onto the column, releasing both calcium and hydrogen ions. The hydrogen release causes the drop in the $\mathrm{pH}$ of the solution passing down the column. In columns where the percent conversion to the calcium form was greater, less hydrogen was released into the system to lower the $\mathrm{pH}$ of the medium passing through the remainder of the column (fig. 4). For the 20-percent converted beads (approx. IEM pH of 4.9) in figure 4, substantial hydrogen ions are released, dropping the $\mathrm{pH}$ of the medium to about 3 . For higher lead concentrations, the effect would be even more dramatic. From figure 1, the equilibrium concentration of lead in the solution over the IEM at $\mathrm{pH} 3$ should be 60 percent of the original concentration, which is what was observed in the effluent. In all other studies, 80 -percent converted beads were used and the $\mathrm{pH}$ of the effluent was monitored as samples were collected. Examination of the $\mathrm{pH}$ profiles for each column experiment is required for the correct interpretation of results. Interpretations tend to be complicated by a drifting $\mathrm{pH}$ and the inability to maintain the influent $\mathrm{pH}$ during runs, even for the highly acetate-buffered test solutions. Figures 5 and 6 show the effect of the column on the $\mathrm{pH}$ of the challenge solution. Figure 5 demonstrates that the column attempts to adjust the $\mathrm{pH}$ to a value coincidentally equal to the $\mathrm{pKa}$ of the ion-exchange material. A good linear correlation of the amount of $\mathrm{pH}$ adjustment initially performed by the column on the challenge solution to adjust the $\mathrm{pH}$ toward 5.6 is shown in figure 6 . Other percent conversions would be expected to produce a similar effect, although the $\mathrm{pH}$ value converged upon should be different. In an unrelated experiment using the large beads to develop a home test kit for determination of lead (ppb level) in drinking water that also contained copper and zinc (ppm range), the $\mathrm{pH}$ of the challenge solutions was buffered to values between 3.8 and 4.5. At the lower $\mathrm{pH}$, the majority of the lead and a small fraction of the copper is retained on the column whereas no zinc is collected. At the higher $\mathrm{pH}$, lead and the majority of the copper are retained by the column but only a small fraction of the zinc is removed from the challenge solution. These experiments further illustrate the effect of $\mathrm{pH}$ on the retention of metal ions on this ion-exchange material.

The optimization of column conditions presented in figures 7 and 8 are as expected. The larger columns provide more reasonable looking curves as flow patterns in the columns are more homogeneous. Slower flow rates provide better equilibration, particularly with respect to mass transfer in the ion-exchange media. Based upon the results of these experiments, subsequent experiments used $1 \mathrm{~g}$ of ion-exchange material and a flow rate of $2 \mathrm{ml} / \mathrm{min}$. The higher, unoptimized flow rate was used to expedite breakthrough conditions. The effect of ionic strength observed in figure 7 is the result of several simultaneous processes, an advanced discussion of which is beyond the scope of this report. Briefly, the processes leading to the improved performance of the ion-exchange material include a combination of the change in activity of the exchanging ions along with a lowering of the surface tension of the solution. The ionic strength alters the activity of the exchanging ions in predictable fashion. The change in surface tension promotes mass transfer across the interface between the solution and ion-exchange resin. 
A major drawback of the IEM is that mass diffusion in the resin is a limiting factor for the breakthrough of lead. As the flow rate is slowed, there is more time for lead at the surface of the resin to diffuse inwardly. Hence, in figure 8, the amount of lead removed per gram of IEM is dramatically improved at a flow rate of $0.5 \mathrm{ml}$ per minute. Because the intent of these experiments was to amplify the differences in column performance by various conditions in the challenge solutions, higher flow rates than optimal were used. The actual performance of the columns used in the following experiments could be greatly improved if a slower flow rate were used. The problems associated with mass transfer in the IEM are confirmed in figure 9, which indicates that $\mathrm{Pb}$ loading of about 10 percent by weight leads to breakthrough for unoptimized conditions. To give a perspective, the 0.5 -ml-per-minute data having $\mathrm{Ci} / \mathrm{Ce}=0.0004$ at the end of the run has a loading of 17 percent by weight ( 38 percent of theoretical). This indicates that optimizing the conditions allows considerably more lead to be removed before breakthrough is approached.

Chloride ion weakly complexes lead ion and in addition, lead chloride is sparingly soluble. From equilibrium constant calculations, the solubility of the lead is complete under all conditions tested, including that in the presence of 0.1-molar excess chloride ion. Furthermore, the concentrations of $\mathrm{PbCl}^{+}$and $\mathrm{PbCl}_{3}^{-}$are negligible at $500-\mathrm{ppm} \mathrm{Pb}$ with 0.1 -molar excess chloride ion. ${ }^{16}$ In a preliminary experiment at $\mathrm{pH} 5.5$ using $107-\mathrm{ppm}$ lead chloride pumped at $2 \mathrm{ml} / \mathrm{min}$ through a $10-\mathrm{mm}$-id column containing $1.00 \mathrm{~g}$ of 80 -percent converted IEM, the lead concentration in the column effluent was lowered to below the limit of instrumental detection $(<2 \mathrm{ppb} \mathrm{Pb})$ throughout the run (total volume of $240 \mathrm{ml}$ ). Effluent lead concentrations in the low-ppb range were typical of the IEM performance prior to column breakthrough for challenge solutions containing modest lead concentrations. Figure 10 illustrates the effect of various anions on the retention of lead. The interpretation of the figure is complicated by the effect of $\mathrm{pH}$ on the system. Plots for nitrate are complicated by the drift of the $\mathrm{pH}$ to unfavorable absorption values toward the end of the run. The $\mathrm{pH}$ started in the 5.8 range and drifted toward 4 or less for the last data points, demonstrating that lead preferentially displaces calcium over hydrogen. The chloride curves have a less pronounced $\mathrm{pH}$ effect and exhibit the same general trend as that for the ionic strength curves presented in figure 7 . The last data points on the chloride curves show that in the presence of 0.1 -molar excess chloride, the $\mathrm{Pb}$ is retained more effectively, even with slightly less favorable $\mathrm{pH}(\mathrm{pH}=5.5$ vs. 5.3 for the excess-anion run).

Acetate is a complexing anion that neutralizes the charge on the lead, rendering it a neutral species. ${ }^{16}$ According to the values of the stepwise formation constants, appreciable amounts of $\mathrm{PbAc}^{+}$can be generated as the acetate proceeds to form the neutral $\mathrm{PbAc}_{2}$ species. Either the $\mathrm{Pb}^{2+}$ or the $\mathrm{PbAc}^{+}$ion is capable of immediately adsorbing to the IEM; however, the equilibrium is probably reestablished rapidly enough to produce substantial cationic species as the IEM removes the lead from solution. Nonetheless, acetate competes markedly with the IEM for lead. For 500-ppm Pb prepared from lead acetate, substantial amounts of the lead are in cationic species at $\mathrm{pH} 4$ where the IEM is less effective. As the $\mathrm{pH}$ rises to 5 and 6 , the amount of cationic species is on the order of two-thirds and one-half, respectively (exact calculations rely on an iterative process). In the presence of a large excess of acetate ( 0.1 molar), the calculations are more exact and the concentrations of cationic lead drop markedly from $\mathrm{pH} 4$ (2 percent $\mathrm{Pb}^{2+}$ and 1 percent $\mathrm{PbAc}^{+}$) to $6\left(<0.5\right.$ percent $\mathrm{Pb}^{2+}$ plus $\mathrm{PbAc}^{+}$). Under these conditions, the rapid establishment of equilibrium in the solution enables the IEM to remove lead successfully (see fig. 10). The lead breakthrough correlates directly with the amount and strength of competing ligands in solution. In unrelated beaker experiments with zinc and IEM films, similar results were achieved with EDTA. None of the zinc was removed from the solution by the IEM because of the complexing strength of the ligand that creates an anionic complex, ZnEDTA $^{2-}$.

A final note regarding the often-detrimental effects of calcium in the matrices is that this resin operates most effectively in the calcium form for all divalent cations that have been tested with the IEM to date. This point is further demonstrated in the excess-anion experiments wherein the matrix is approximately 0.005 molar (200 ppm) in calcium. In experiments performed stripping lead from seawater, the effect of sodium was to eventually displace calcium and expand the resin, causing deterioration of the IEM and column performance. To this end, we spiked the matrices with small amounts of calcium to replenish the resin as the experiment proceeded. In all experiments using excess, noncomplexing anions, results were superior to runs without the excess anions. These results are more likely due to ionic strength considerations than to calcium enhancement.

\footnotetext{
"Unpublished results of Dr. J. Gorse, Department of Chemistry, Baldwin Wallace College, Berea, OH, March, 1993.
} 


\section{Conclusion}

The ion-exchange material (IEM), developed from battery separator technology, is composed of cross-linked polyvinyl alcohol and entrapped polyacrylic acid and can be produced in a variety of forms. The current evaluation is designed to demonstrate the ability of the material as a replacement for column ion exchangers where weak acid exchangers are applicable. Data are presented for lead $(\mathrm{Pb})$ adsorption under a number of physical and chemical conditions. Physical conditions were several geometries, the quantity of IEM in the test column, and flow rates. The chemical conditions were lead concentration, $\mathrm{pH}$, ionic strength, and effect of weakly competing organic complexing agents. The ion-exchange material removed lead effectively under most conditions; however, the breakthrough characteristics for similar columns were greatly affected by $\mathrm{pH}$ and the presence of complexing anions. Under ideal conditions, this ion-exchange material will remove modest amounts of lead (high-ppm concentration range) and reduce the $\mathrm{Pb}$ concentration to the low-ppb range.

\section{References}

1. Xintaras, Charles. Analysis Paper: Impact of Lead-Contaminated Soil on Public Health; U.S. Department of Health and Human Services: Atlanta, GA, 1992.

2. U.S. Environmental Protection Agency. Literature Review Summary of Metals Extraction Processes Used to Remove Lead From Soils, Project Summary; EPA/600/SR-94/006; National Service Center for Environmental Publications: Cincinnati, OH, 1994.

3. U.S. Environmental Protection Agency. Remedial Action, Treatment and Disposal of Hazardous Waste; EPA/600/9-91/002; Risk Reduction Engineering Laboratory: Cincinnati, OH, 1991.

4. Philipp, Warren H.; May, Charles E. New Ion Exchange Membranes; NASA TM-81670; NASA Lewis Research Center: Cleveland, OH, 1980.

5. Philipp, Warren H.; May, Charles E. Kinetics of Copper Ion Absorption by Cross-Linked Calcium Polyacrylate Membranes; NASA TM-83052; NASA Lewis Research Center: Cleveland, OH, 1983.

6. May, Charles E.; Philipp, Warren H. Ion Exchange Selectivity for Cross-Linked Polyacrylic Acid; NASA TM-83427; NASA Lewis Research Center: Cleveland, OH, 1983.

7. May, Charles E. Kinetics of Chromium Ion Absorption by Cross-Linked Polyacrylate Films; NASA TM-83661; NASA Lewis Research Center: Cleveland, OH, 1984.

8. Philipp, Warren, H.; Street, Kenneth W., Jr. Ion Exchange Polymers and Method for Making; U.S. Patent 5,371,110; December 6, 1994.

9. Hill, C.M.; Street, K.W.; Philipp, W.H.; Tanner, S.P. Determination of Copper in Tap Water Using Solid-Phase Spectrophotometry; Anal. Lett. 1994, 27, 2589-2599.

10. Uy, O. Manuel; Ginther, Mike J.; Folkerts, John T.; and Street, Jr., Kenneth W. Use of a NASA-Developed Ion Exchange Material for Removal of Zinc from Electroplating Baths; Johns Hopkins APL Tech. Dig. 1996, 17, 371-376.

11. Tanner, Stephen P.; Street, Kenneth W., Jr. Solid-Phase Luminescence of Several Rare Earth Ions on IonExchange Films; Appl. Spect. 2000, 54, 669-675.

12. Hill, C.M.; Street, K.W.; Tanner, S.P.; Philipp, W.H. Preparation of Ion Exchange Films for Solid-Phase Spectrophotometry and Solid-Phase Fluorometry; Anal. Lett. 2000, 33, 2779-2792.

13. Schlameus, Herman Wade; Barlow, Dareen Eugene Method for Preparing Polymeric Beads; U.S. Patent 5,959,073; September 28, 1999.

14. U.S. Environmental Protection Agency. Proposed Update Number III: Physical/Chemical Methods Test Methods for Evaluating Solid Waste; Method 7471A, rev. 1, SW-846, Government Printing Office: Washington, DC, 1994.

15. Standard Methods for the Examination of Water and Wastewater; 15th ed., American Public Health Association: Washington, DC, 1980.

16. Ringbom, Anders. Complexation in Analytical Chemistry: A Guide for the Critical Selection of Analytical Methods Based on Complexation Reactions; R.E. Krieger Pub. Co.: Huntington, NY, 1979. 
TABLE 1.-RECOVERY OF LEAD FROM VARIOUS MATRICES

\begin{tabular}{|r|c|c|c|c|}
\hline \multicolumn{7}{|c|}{$\begin{array}{c}\text { Lead recovered in ion-exchange material, } \\
\text { percent (std deviation) }\end{array}$} & $\begin{array}{c}\text { Hydrogen ion } \\
\text { concentration, } \\
\mathrm{pH}\end{array}$ \\
\hline None & Nitrate & Chloride & Acetate & \\
\hline \multicolumn{6}{|c|}{10 -ppm lead with 0.1-molar anion } \\
\hline $92.2(0.4)$ & 92 & 91 & 81 & 5.0 \\
$9.2(3.6)$ & 21 & $5.5(0.5)$ & 0 & 3.0 \\
\hline \multicolumn{6}{|c|}{100 -ppm lead with 0.1-molar anion } \\
\hline $9.2(2.4)$ & 15 & 8 & 1 & 3.0 \\
\hline \multicolumn{7}{|c|}{500 -ppm lead with 0.1-molar anion } \\
\hline $10.4(3.9)$ & 16.2 & 11 & 14 & 3.0 \\
\hline
\end{tabular}

${ }^{\mathrm{a}} \mathrm{Standard}$ deviation between replicate experiments.

TABLE 2.-CAPACITY AND LEAKAGE OF ION-EXCHANGE

\begin{tabular}{|c|c|c|c|c|}
\hline \multicolumn{1}{|c|}{$\begin{array}{c}\text { Bead size, } \\
\mu \mathrm{m}\end{array}$} & \multicolumn{2}{|c|}{ Capacity } & \multicolumn{2}{c|}{ Leakage } \\
\cline { 2 - 5 } & meq/g & $\begin{array}{c}\text { Standard } \\
\text { deviation }^{\mathrm{a}}\end{array}$ & $\mathrm{meq} / \mathrm{g}$ & $\begin{array}{c}\text { Standard } \\
\text { deviation }^{\mathrm{a}}\end{array}$ \\
\hline$<250$ & 4.2 & ----- & ----- & ----- \\
250 to 600 & $\mathrm{~b}^{\mathrm{b}} 4.3$ & 0.07 & $\mathrm{~b} 0.4$ & 0.03 \\
600 to 1400 & 5.4 & .02 & 1.2 & .02 \\
\hline
\end{tabular}

${ }^{a}$ Standard deviation, $\mathrm{n}=2$.

${ }^{\mathrm{b}}$ Determined on beads recycled from column testing.

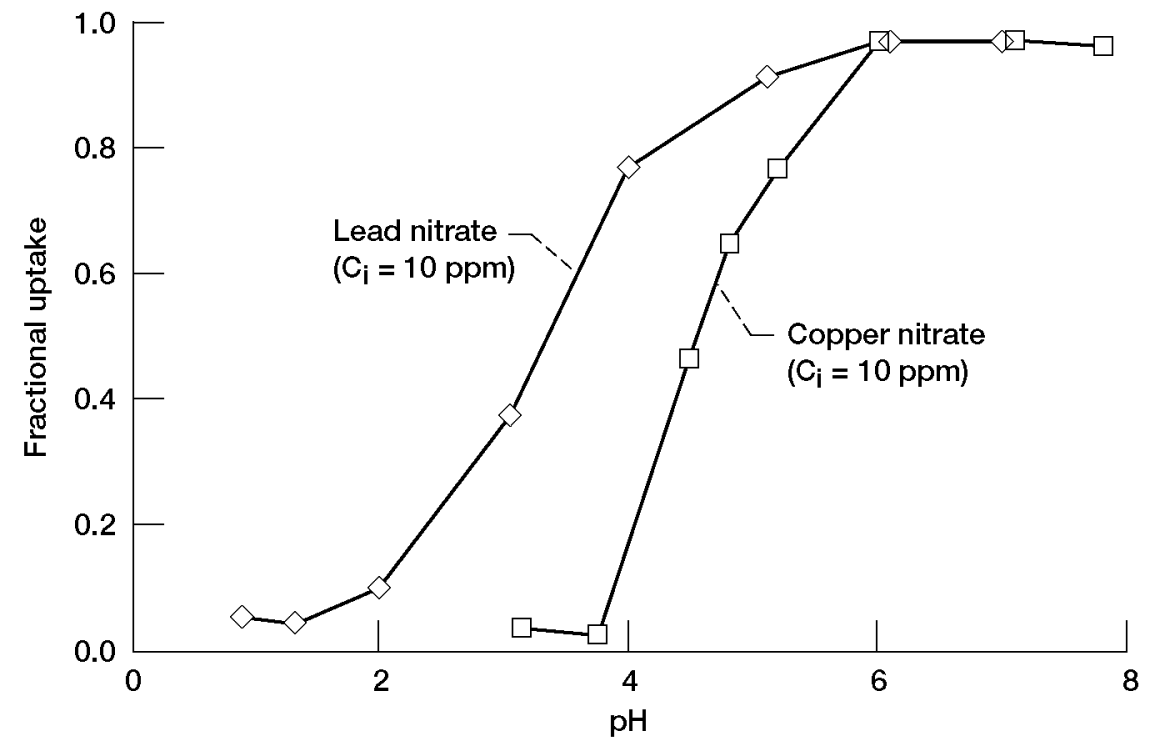

Figure 1.-Fraction of metal removed as function of $\mathrm{pH}$ for calcium (Ca) form of ion-exchange material (IEM) powder. 


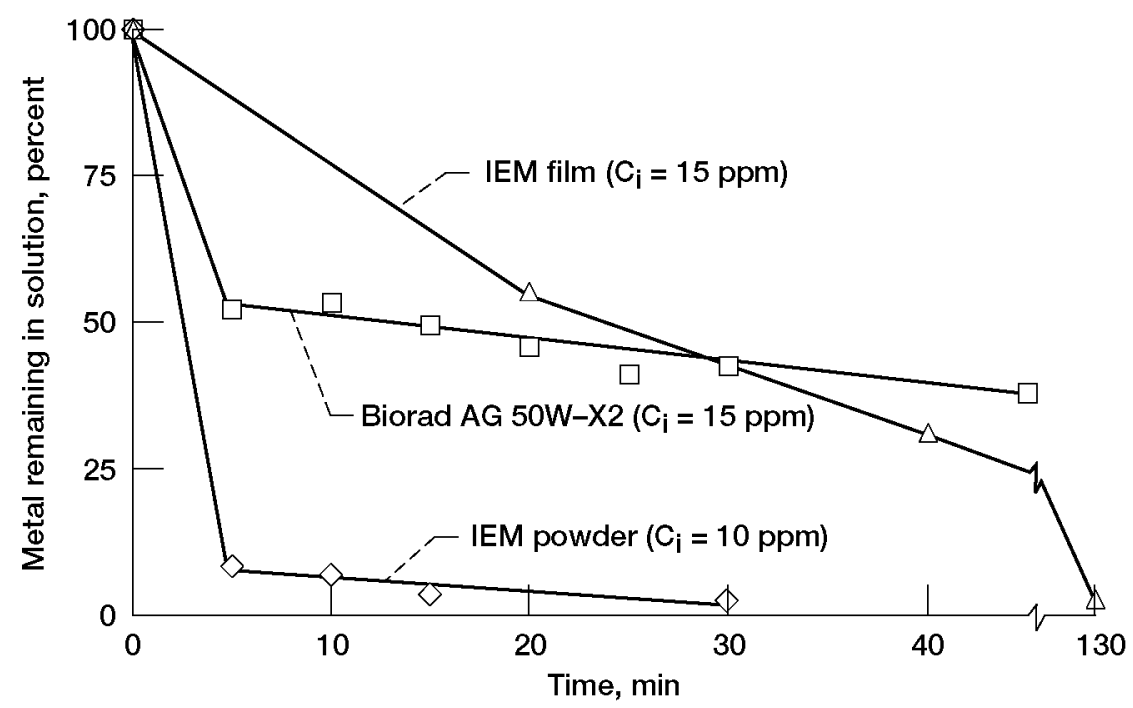

Figure 2.-Metal ion concentration remaining in solution as function of equilibration time for various resins.

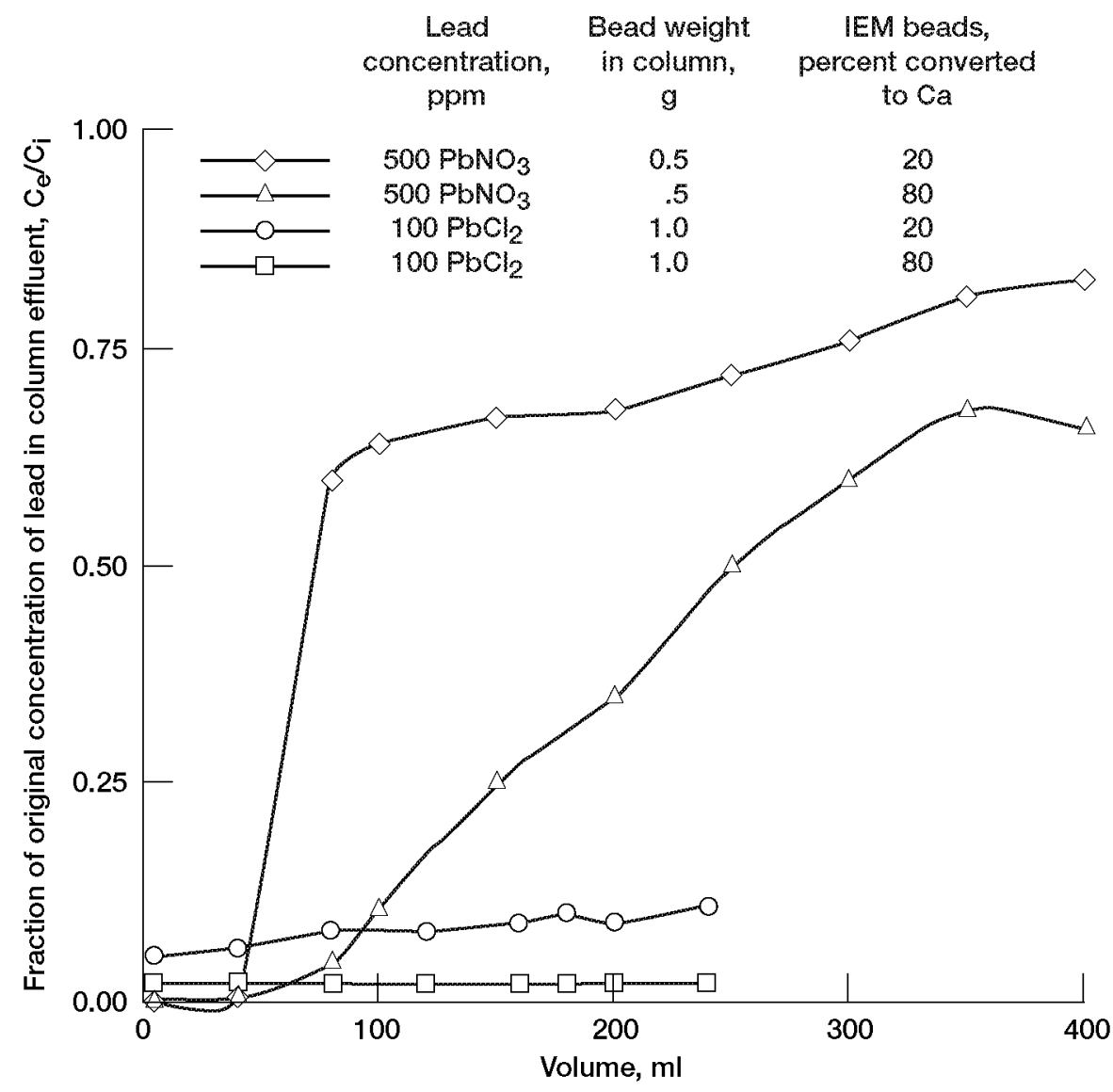

Figure 3.-Fraction of original concentration of lead nitrate $\left(\mathrm{PbNO}_{3}\right)$ and lead chloride $\left(\mathrm{PbCl}_{2}\right)$ in column effluent $\left(\mathrm{C}_{\mathrm{e}} / \mathrm{C}_{\mathrm{i}}\right.$ values $\left.\times 1000\right)$ as function of volume of lead solution through columns for IEM beads 80 and 20 percent converted to calcium form. Flow rate through columns, $1.0 \mathrm{ml} / \mathrm{min}$. 


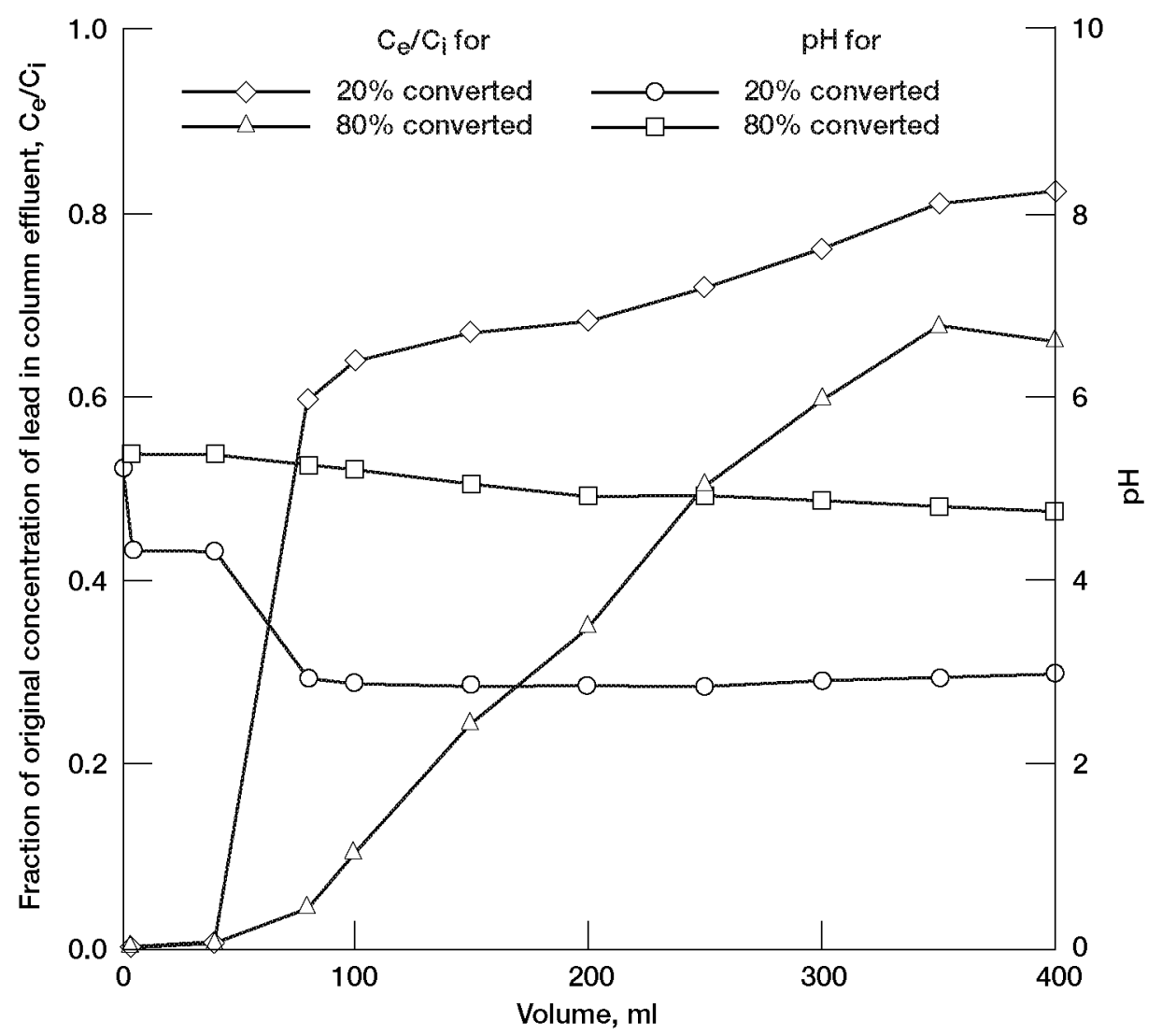

Figure 4.-Correlation of fraction of original concentration of lead in column effluent $\mathrm{C}_{\mathrm{e}} / \mathrm{C}_{\mathrm{i}}$ as function of volume of lead solution through column to $\mathrm{pH}$ of column effluent as function of volume through column for IEM beads 80 percent and 20 percent converted to calcium form. Note: $\mathrm{pH}$ of challenge solution is $\mathrm{pH}$ at volume $=0 \mathrm{ml}$. 


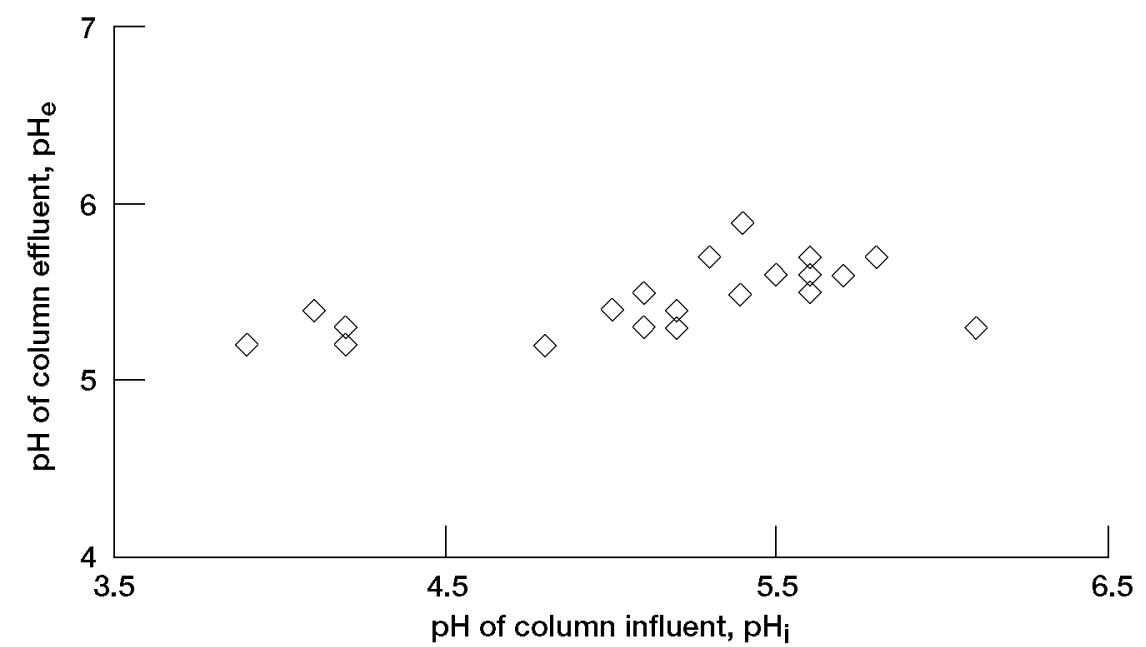

Figure 5.- $\mathrm{pH}$ of column effluent $\mathrm{pH}_{\mathrm{e}}$ as function of $\mathrm{pH}$ of column influent $\mathrm{pH}_{\mathrm{i}}$ $\left(\mathrm{pH}_{\mathrm{i}}\right.$ taken as $\mathrm{pH}$ of challenge solution) for challenge solutions containing nitrate and chloride.

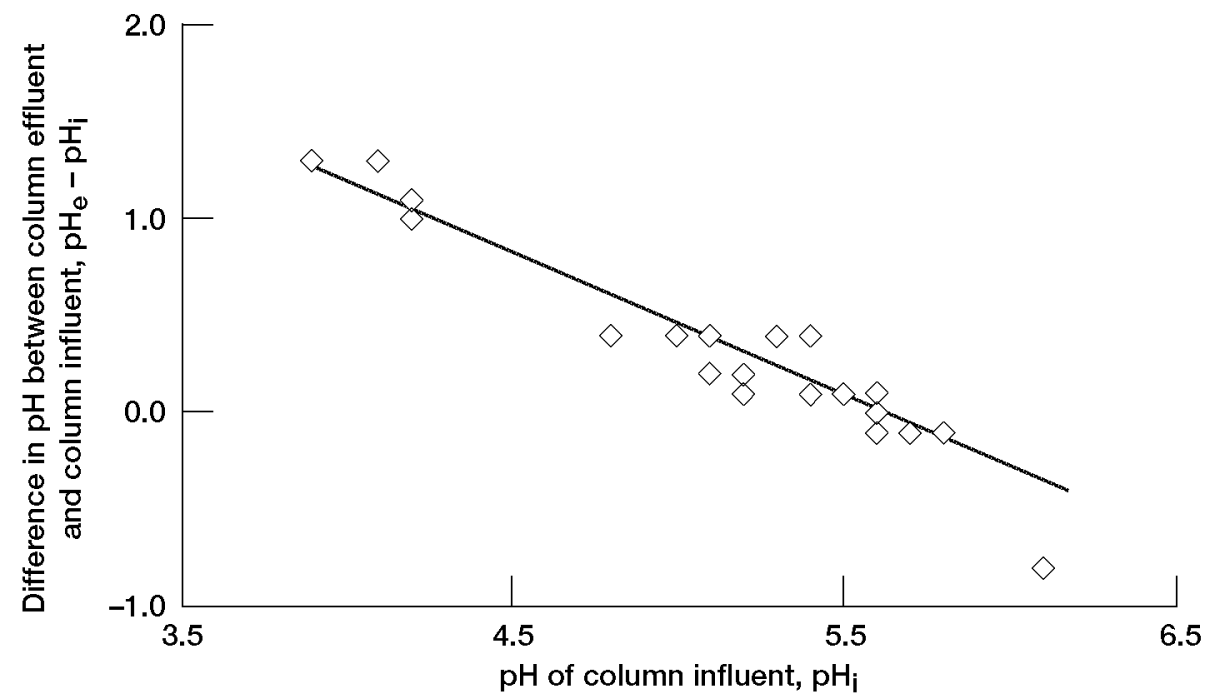

Figure 6.-Difference in $\mathrm{pH}$ between column effluent $\mathrm{pH}_{e}$ and column influent $\mathrm{pH}_{\mathrm{i}}$ $\left(\mathrm{pH}_{\mathrm{i}}\right.$ taken as $\mathrm{pH}$ of challenge solution) as function of $\mathrm{pH}_{\mathrm{i}}$. 


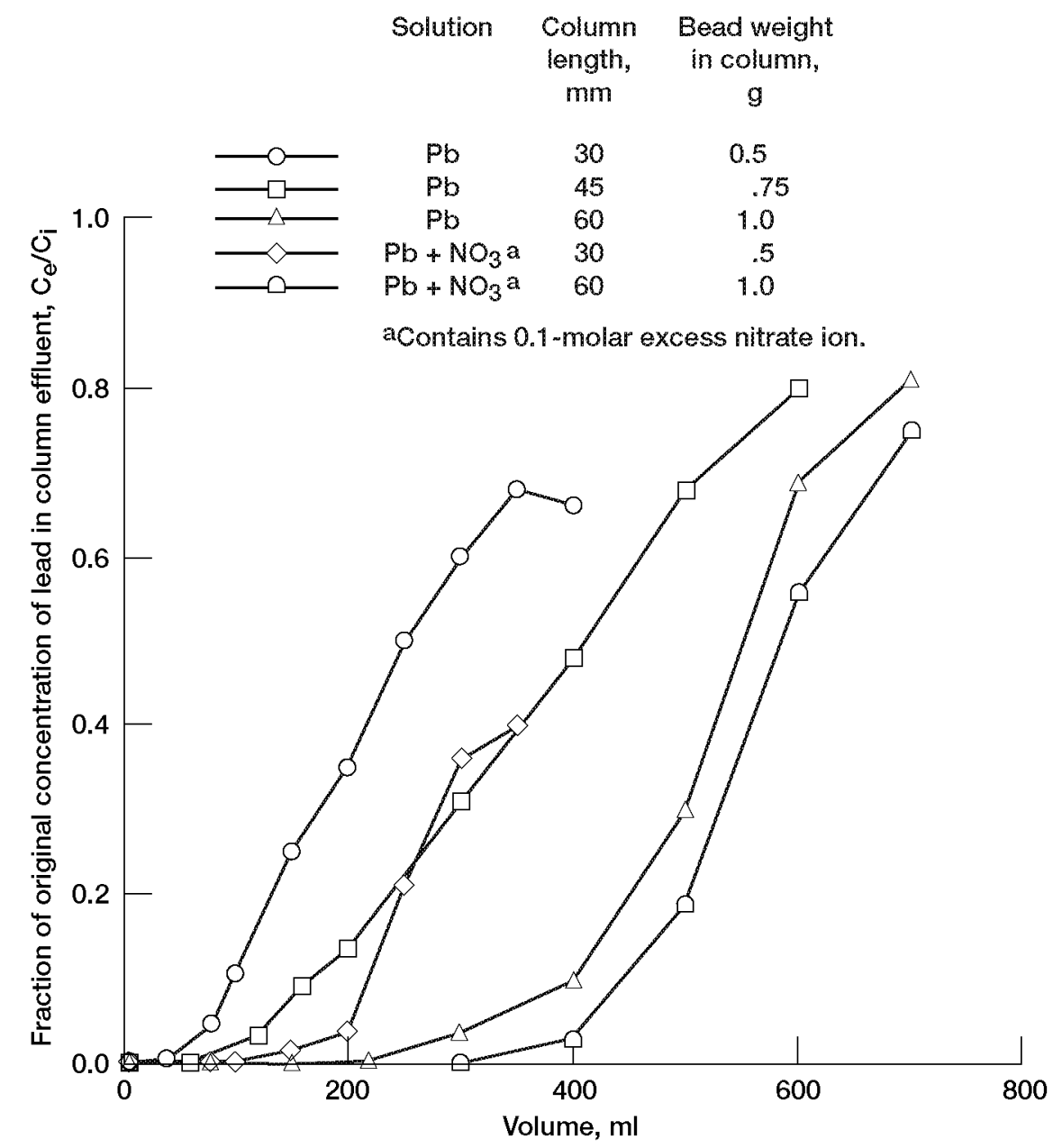

Figure 7.-Fraction of original concentration of lead in column effluent $\left(\mathrm{C}_{\mathrm{e}} / \mathrm{C}_{i}\right)$ as function of volume of lead solution through column for columns of various lengths challenged with low- and high-ionic-strength lead solutions. Flow rate, $2.0 \mathrm{ml} / \mathrm{min}$ of 500 -ppm lead nitrate through 80 -percent IEM converted to calcium form. 


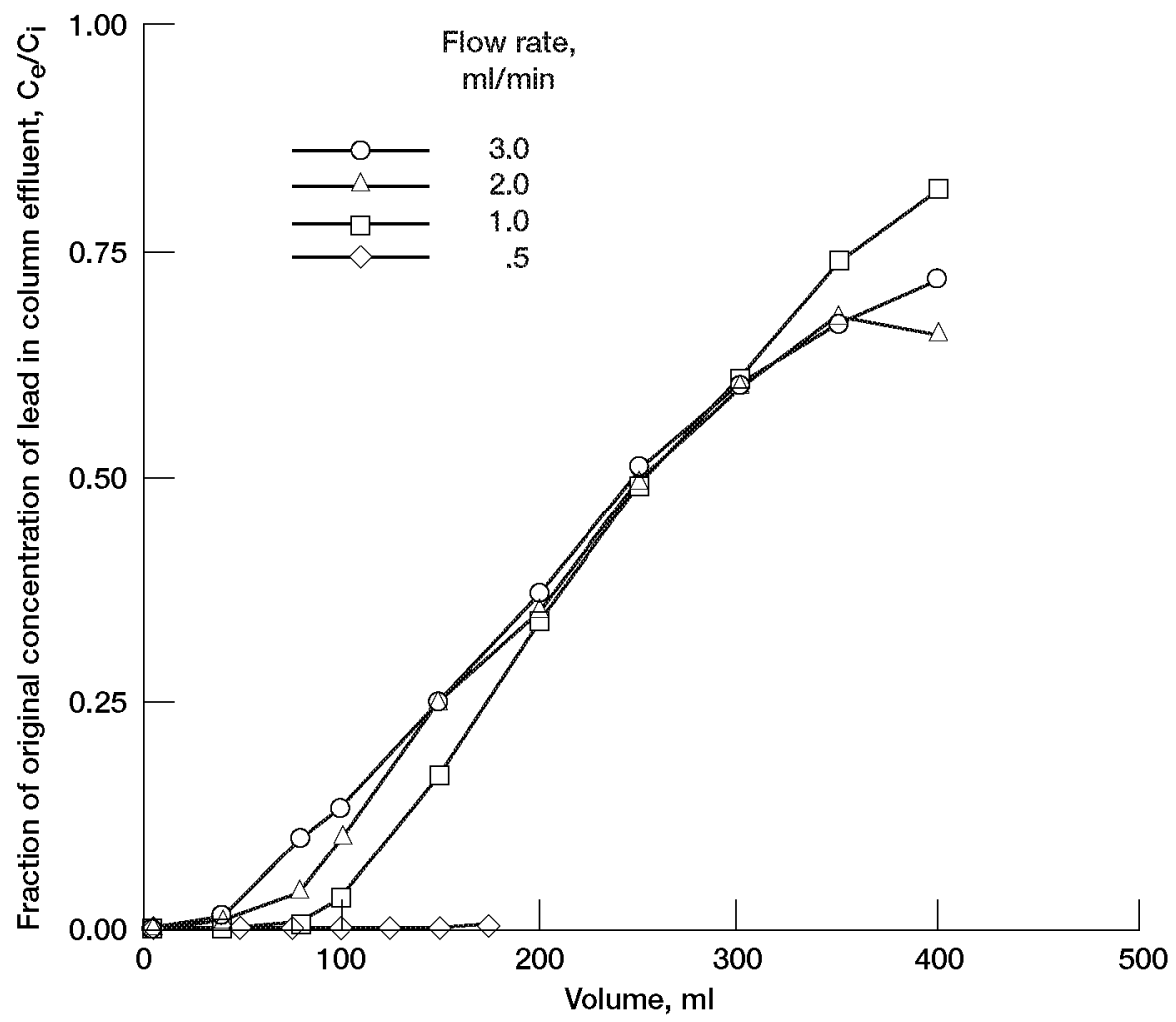

Figure 8.-Fraction of original concentration of lead in column effluent $\left(\mathrm{C}_{\mathrm{e}} / \mathrm{C}_{\mathrm{j}}\right)$ as function of volume of lead solution through column for various flow rates.

Columns contained $0.5 \mathrm{~g}$ of 80 -percent calcium-converted IEM challenged with 500-ppm lead nitrate.

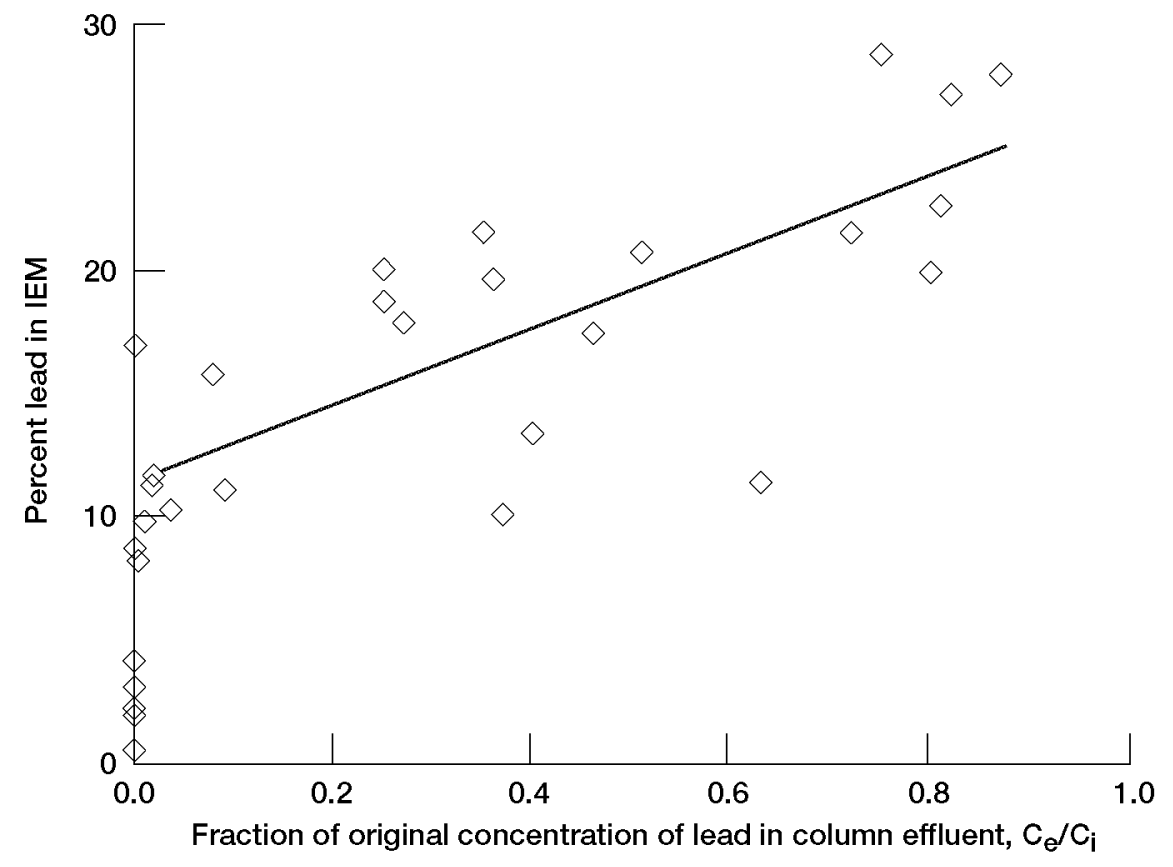

Figure 9.-Weight percent of lead in IEM versus ratio of concentration of lead in column effluent $C_{e}$ for final data point in run divided by concentration of lead in challenge solution $\mathrm{C}_{\mathrm{i}}$. 


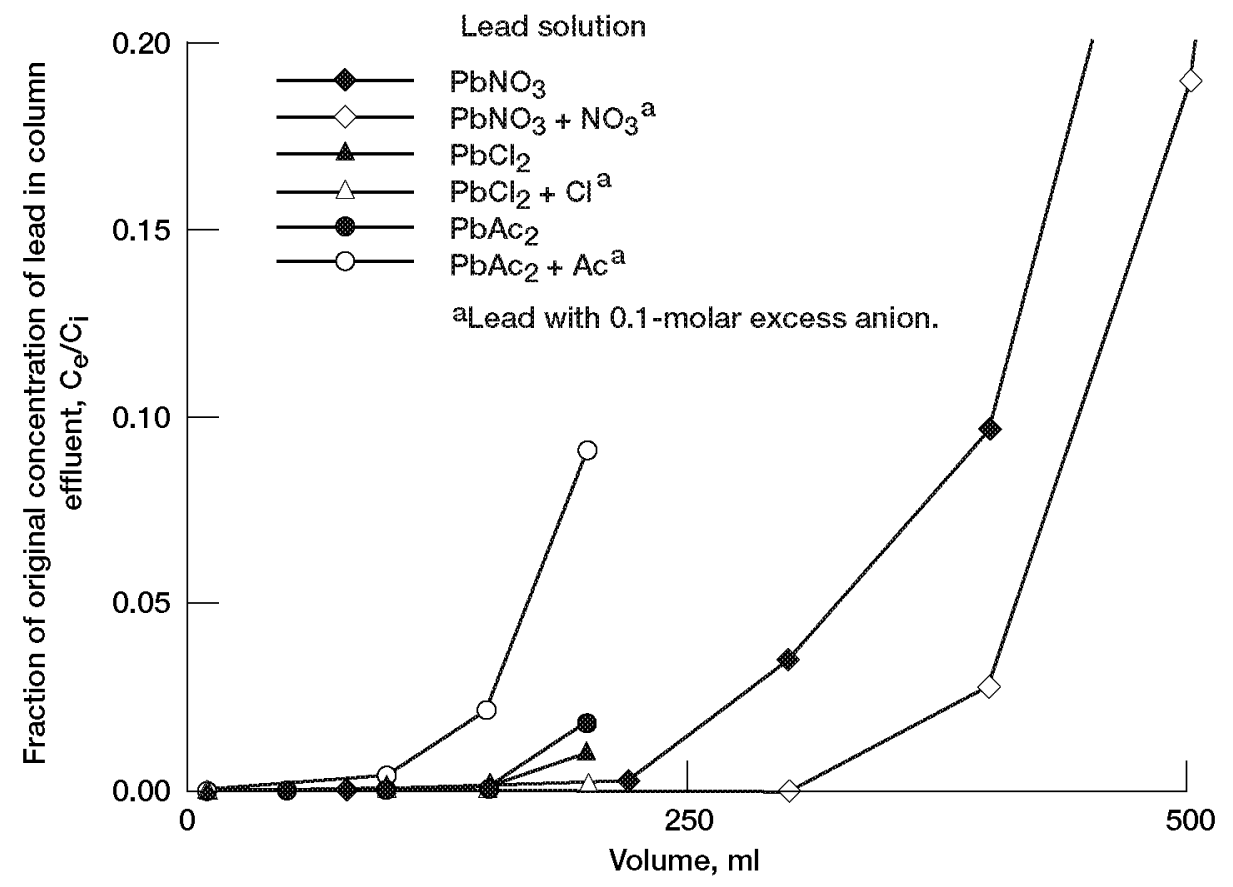

Figure 10.-Fraction of original concentration of lead in column effluent $\left(C_{e} / C_{i}\right)$ as function of volume of lead solution through column for various anions. Lead concentration, $500 \mathrm{ppm}$. 


\section{REPORT DOCUMENTATION PAGE}

Public reporting burden for this collection of information is estimated to average 1 hour per response, including the time for reviewing instructions, searching existing data sources, gathering and maintaining the data needed, and completing and reviewing the collection of information. Send comments regarding this burden estimate or any other aspect of this collection of information, including suggestions for reducing this burden, to Washington Headquarters Services, Directorate for Intormation Operations and Reports, 1215 Jefferson Davis Highway, Suite 1204, Arlington, VA 22202-4302, and to the Office of Management and Budget, Paperwork Reduction Project (0704-0188), Washington, DC 20503.

\section{\begin{tabular}{l|l|l} 
1. AGENCY USE ONLY (Leave blank) & 2. REPORT DATE & 3. REPORT TYPE AND DATES COVERED
\end{tabular}}

\section{TITLE AND SUBTITLE}

July 2002

Technical Memorandum

Lead Removal From Synthetic Leachate Matrices by a Novel

Ion-Exchange Material

6. AUTHOR(S)

Kenneth W. Street, Jr., Edward S. Hovanitz, and Sulan Chi

7. PERFORMING ORGANIZATION NAME(S) AND ADDRESS(ES)

National Aeronautics and Space Administration

John H. Glenn Research Center at Lewis Field

Cleveland, Ohio 44135-3191

5. FUNDING NUMBERS

9. SPONSORING/MONITORING AGENCY NAME(S) AND ADDRESS(ES)

National Aeronautics and Space Administration

Washington, DC 20546-0001

8. PERFORMING ORGANIZATION

REPORT NUMBER

E-12932-1

10. SPONSORING/MONITORING AGENCY REPORT NUMBER

NASA TM-2002-211090

\section{SUPPLEMENTARY NOTES}

Kenneth W. Street, Jr., NASA Glenn Research Center; Edward S. Hovanitz, Engelhard Corporation, Elyria, Ohio 44035; and Sulan Chi, Eli Lilly \& Company, Clinton, Indiana 47842. Responsible person, Kenneth W. Street, Jr., organization code 5960, 216-433-5032.

\section{2a. DISTRIBUTION/AVAILABILITY STATEMENT}

12b. DISTRIBUTION CODE

Unclassified - Unlimited

Subject Category: 23

Distribution: Nonstandard

Available electronically at http:/gltrs.grc.nasa.gov/GLTRS

This publication is available from the NASA Center for AeroSpace Information, 301-621-0390.

13. ABSTRACT (Maximum 200 words)

This report discusses the application of a novel polyacrylate-based ion-exchange material (IEM) for the removal of lead $(\mathrm{Pb})$ ions from water. Preliminary testing includes the establishment of the operating $\mathrm{pH}$ range, capacity information, and the effect of calcium and anions in the matrix. Batch testing with powder indicates slightly different optimal operational conditions from those used for column testing. The ion exchanger is excellent for removing lead from aqueous solutions.

\begin{tabular}{|c|c|c|c|}
\hline \multirow{2}{*}{\multicolumn{3}{|c|}{$\begin{array}{l}\text { 14. SUBJECT TERMS } \\
\text { Ion exchange; Lead; Water }\end{array}$}} & \multirow{3}{*}{$\begin{array}{l}\text { 15. NUMBER OF PAGES } \\
20 \\
\text { 16. PRICE CODE } \\
\text { 20. LIMITATION OF ABSTRACT }\end{array}$} \\
\hline & & & \\
\hline $\begin{array}{l}\text { 17. SECURITY CLASSIFICATION } \\
\text { OF REPORT } \\
\text { Unclassified }\end{array}$ & $\begin{array}{l}\text { 18. SECURITY CLASSIFICATION } \\
\text { OF THIS PAGE } \\
\text { Unclassified }\end{array}$ & $\begin{array}{l}\text { 19. SECURITY CLASSIFICATION } \\
\text { OF ABSTRACT } \\
\text { Unclassified }\end{array}$ & \\
\hline NSN 7540-01-280-5500 & & & $\begin{array}{l}\text { andard Form } 298 \text { (Rev. 2-89) } \\
\text { escribed by ANSI Std. Z39-18 } \\
8-102\end{array}$ \\
\hline
\end{tabular}

